О. О. Колбасюк

Волинський науково-дослідниц

експертно-криміналістичний иентр МВС Украӥни

O. Kolbasiuk

Volyn Scientific Research Forensic Centre, MIA of Ukraine

\title{
ОСОБЛИВОСТІ МЕТОДІВ ДОСЛІДЖЕННЯ ВИБУХОВИХ РЕЧОВИН, ПРОДУКТІВ ВИБУХУ І ПОСТРІЛУ
}

\section{THE PECULIARITIES OF EXAMINATION METHODS OF EXPLOSIVES, EXPLOSION PRODUCTS AND GUNSHOT RESIDUE}

Мета статті - окреслити сферу найефективнішого застосування спектроскопічних методів ідентифікації вибухових речовин, грунтуючись на всебічному порівняльному аналізі їх переваг і хиб, уточнити підходи до розвитку цих методів. У процесі дослідження схарактеризовано найбільш перспективні спектроскопічні методи виявлення та ідентифікації вибухових речовин і продуктів вибуху, які натепер ще не набули широкого застосування в органах Національної поліції та підрозділах Експертної служби МВС, а саме: спектроскопія іонної рухливості, лазерно-іскрова емісійна спектроскопія, раманівська спектроскопія, терагерцова спектроскопія. Виокремлено переваги кожного із зазначених методів щодо швидкості, інформативності, селективності дослідження, у тому числі дистанційного, можливості дослідження слідових кількостей вибухових речовин, їх випарів, мікроскопічних частинок, що входять до їх складу. Систематизовано недоліки методів, запропоновано шляхи їх послаблення чи усунення. Доведено, зважаючи на можливості кожного окремого методу, перспективність їх комбінування і проілюстровано прикладами такого поєднання. Конкретизовано, виходячи із завдань забезпечення безпеки пересічних громадян, відновлення середовищ з високим ризиком для життя, тематику актуальних перспективних розробок із метою удосконалення наявних і розвитку нових технологій дослідження зазначених речовин. Достовірність отриманих результатів і висновків забезпечено використанням системного підходу до проведення дослідження, застосуванням фізичних методів дослідження для виявлення та аналізу вибухових речовин і продуктів вибуху, загальнологічних методів, зокрема синтезу й аналізу, а також порівняння та узагальнення - для формулювання об'єктивних висновків щодо застосування фізичних методів у практичній діяльності.

Ключові слова: спектроскопія іонної рухливості; лазерно-іскрова емісійна спектроскопія; раманівська спектроскопія; терагерцова спектроскопія; вибухові речовини.

Цель статьи - определить сферу наиболее эффективного применения спектроскопических методов идентификации взрывчатых веществ, основываясь на всестороннем сравнительном анализе их преимуществ и недостатков, уточнить подходы к развитию этих методов. В процессе исследования охарактеризованы наиболее перспективные спектроскопические методы обнаружения и идентификации взрывчатых веществ и продуктов взрыва, которые на данный момент еще не получили широкого применения в органах Национальной полиции и подразделениях Экспертной службы МВД, а именно: спектроскопия ионной подвижности, лазерно-искровая эмиссионная спектроскопия, рамановская спектроскопия, терагерцовая спектроскопия. Уточнены преимущества каждого из указанных методов по скорости, информативности, селективности исследования, в том числе дистанционного, возможности исследования следовых количеств взрывчатых веществ, их испарений, микроскопических частиц, входящих в их состав, систематизирована недостатки методов, предложены пути их ослабления или устранения. Доказана, учитывая возможности каждого отдельного метода, перспективность их комбинирования и проиллюстрирована примерами такого сочетания. Конкретизирована, исходя из задач обеспечения безопасности рядовых граждан, восстановления среды с высоким риском для жизни, тематика актуальных перспективных 
разработок с целью усовершенствования существующих и развития новых технологий исследования указанных веществ. Достоверность полученных результатов и выводов обеспечена использованием системного подхода к проведению исследования, применением физических методов исследования для выявления и анализа взрывчатых веществ и продуктов взрыва, общелогических методов, в частности синтеза и анализа, а также сравнения и обобщения - для формулирования объективных выводов по применению физических методов в практической деятельности.

Ключевые слова: спектроскопия ионной подвижности; лазерно-искровая эмиссионная спектроскопия; рамановская спектроскопия; терагерцовая спектроскопия; взрывчатые вещества.

The aim of the article is to outline the sphere of the most efficient use of spectroscopic methods of identifying explosives, based on the comprehensive comparative analysis of their advantages and disadvantages, while specifying ways of development of these methods. During the research, some of the most advanced spectroscopic methods for revealing and identification of explosives and explosive products have been outlined that have not yet become widely used by the National Police bodies and Ministry of Internal Affairs of Ukraine offices, mainly: Ion Mobility Spectrometry, Laser Spark Emission Spectroscopy, Raman Spectroscopy, and Terahertz Spectroscopy. Advantages have been highlighted for each of the aforementioned methods reference the speed, informational content, and selectiveness of research-including remote research-and the possibility of investigating traces of explosives, vapours, and microscopic particles that form part of them. The disadvantages of these methods have been systemised, ways of alleviating or removing them suggested. The advanced way of combining the methods has been proven-whilst taking each individual capabilities consideration-and illustrated with examples of those combinations. With the purpose of providing security for civilians and restoration of high-risk environments, the topics of relevant advanced developments have been specified aiming at improving the existing and development of new technologies of research for the aforementioned substances. The reliability of obtained results and conclusions is ensured through the systematic approach to research, the use of physical methods of research for identification and analysis of explosives and explosion products, common methods of Logics, including synthesis and analysis as well as comparison and generalisation - in order to provide objective conclusions for the use of physical methods in practical activity.

Keywords: Ion Mobility Spectrometry; Laser Spark Emission Spectroscopy; Raman Spectroscopy; Terahertz Spectroscopy; explosives.

Актуальність дослідження вибухових речовин (далі - ВР) зумовлена насамперед необхідністю забезпечення внутрішньої безпеки країни, своєчасного виявлення та усунення можливих загроз. А отже поглиблене вивчення вибухонебезпечних речовин, подальший розвиток методів їх виявлення та дослідження становить перспективний напрям наукових розвідок.

Вибухові речовини були предметом дослідження багатьох учених, серед них: Дж. Готтфрід (J. L. Gottfried), Ф. ДеЛусія (F. C. DeLucia), А. Мізіолек (A. W. Miziolek), Д. Русак (D. A. Rusak), Є. Їнон (J. Yinon), Ф. Запата (F. Zapata), Дж. Стейнфілд (J. Steinfeld) та ін. Проте більш грунтовного вивчення потребують спектроскопічні (зокрема, спектроскопія іонної рухливості (Ion mobility spectrometry, далі - IMS), лазерно-іскрова емісійна спектроскопія (Laser-induced breakdown spectroscopy, далі - LIBS), раманівська спектроскопія (Raman spectroscopy, далі - RS) і терагерцова спектроскопія, далі - THz) методи виявлення та ідентифікації ВР, які натепер ще не набули широкого застосування в структурах MBC та експертних установах (Existing and potential, 2004).

Мета статті - окреслити сферу найефективнішого застосування зазначених методів ідентифікації ВР, грунтуючись на всебічному порівняльному аналізі їх переваг і хиб, уточнити підходи до розвитку цих методів.

Спектроскопічні методи аналізу речовин загалом є доволі поширеними інформативними методами, застосовуваними для ідентифікації речовин, визначення їх кількості та структури, вивчення механізмів перебігу хімічних реакцій тощо. В їх основі лежать дослідження спектрів поглинання або випромінювання речовинами електро- 
магнітних хвиль - сукупності значень певних величин, що характеризують речовину та процеси, які в ній відбуваються. Спектроскопічні методи в аналітичних дослідженнях використовують самостійно. 3 іншими аналітичними методами (хроматографічними, електрофоретичними тощо) їх широко застосовують для детектування (ідентифікації, визначення кількості, структурної організації тощо) низки речовин.

Так, за допомогою IMS вимірюють рухливість іонів (дрейф у потоці інертного газу під дією електричного поля), утворених після іонізації молекул досліджуваної речовини. Іонізовані іони розділяються відповідно до свого розміру та маси і спрямовуються до детектора (Borsdorf, \& Eiceman, 2006). Одержані результати інтерпретують, порівнюючи з відомими стандартами або з бібліотеками відомих ВР.

Останніми роками актуалізувалися дослідження слідових кількостей ВР, їх випарів та мікроскопічних частинок речовин (діапазон мас мікрочастинок, які аналізують методом IMS, зазвичай обмежений значеннями $10^{-14}-10^{-7}$ кг), що входять до складу ВР (це можуть бути як власна ВР, так і технологічні домішки чи продукти розпаду ВР) (Buryakov, 2011). Вибухові пристрої та заряди, споряджені речовинами з низьким тиском парів, можна виявити приладами з технологією IMS завдяки наявності в зарядах домішок із високим тиском парів. Для прикладу, під час аналізу газової проби над зарядом пластиду С-4 гексогену, який є основним компонентом цієї сумішевої ВР, не виявили, проте було зареєстровано високу концентрацію 2-етил-1-гексанолу, що є напівпродуктом синтезу пластифікаторів та циклогексанону (Furton, \& Myers, 2001).

Крім того, у процесі дослідження деяких ВР із порівняно малим вмістом летких домішок в паровій фазі спостерігають високу концентрацію цих домішок під час аналізу. Так, у паровій фазі над зарядом ВР на основі 2,4,6-тринітротолуену (далі - ТНТ), який містить 2,4-динітротолуен (далі - ДНТ) із масовою частиною 0,1 \%, концентрація ДНТ (Murrmann, Jenkins, \& Leggett, 1971; Leggett, Jenkins, \& Murrmann, 1971) майже в 100 разів вища за концентрацію ТНТ.

Оскільки IMS-спектрометр являє собою газоаналізатор, метод відбору проб залежить від агрегатного стану досліджуваної речовини. Використання вихрового повітряного потоку над поверхнею, яку аналізують, а також підвищення десорбції молекул ВР опроміненням досліджуваної площі інфрачервоним або ультрафіолетовим випромінюванням позитивно позначається на ефективності відбору проб (Gorbachev, Ionov, \& Kolomiets, 2006; Gorbachev, Ionov, \& Kolomiets, 2008).

Використання гібридних приладів Solid Phase Micro Extraction - Ion Mobility Spectroscopy (SPME-IMS), а саме техніки твердофазної мікроекстракції дає змогу концентрувати характерні для ВР леткі сполуки з метою подальшого аналізу, сприяє зниженню межі детектування для моно-, ди- та тринітротолуенів і нітробензенів на кілька порядків (Jeannette, Kenneth, \& Almirall, 2005).

Основним фізичним процесом, що лежить в основі техніки (процесу) атомно-емісійного спектрального аналізу LIBS, є утворення високотемпературної плазми, яка індукується коротким лазерним імпульсом. Цівка плазми та світловий потік, який виділяється з неї, дають змогу проаналізувати досліджуваний зразок. Використання LIBS для виявлення BP має низку переваг, серед яких: відсутність потреби пробопідготовки, невелика кількість досліджуваної речовини, швидке отримання результатів, портативність спектроскопів та їх висока чутливість (Gottfried, De Lucia, Munson, \& Miziolek, 2009). Технологія уможливлює як віддалене, так і дистанційне (до 120 м) визначення різних об’єктів дослідження (Sreedhar, Gundawar, \& Rao, 2014; Ctvrtnickova, Mateo, Yanez, \& Nicolas, 2011; Manoj, Junjuri, \& Myakalwar, 2017). 
Незважаючи на очевидні переваги цього методу, він не позбавлений хиб, зумовлених впливом мікрокомпонентів, які містяться в повітрі, на результати дослідження (Lucena, Dona, Tobaria, \& Laserna, 2011). Послабляє вплив атмосферних перешкод використання приладів з подвійним імпульсом - LIBS. У цьому разі кількість атмосферних перешкод зменшується завдяки зниженню щільності атмосферного газу навколо зразка, внаслідок чого уможливлюється розділення гексогену, органічних речовин і дизельного пального (De Lucia, Gottfried, Munson, \& Miziolek, 2007). Крім того, LIBS можна застосовувати на великій відстані, що дає змогу аналізувати зразки в слідових кількостях, а також в небезпечних і несприятливих умовах (Bohling et al., 2007; Lazic et al., 2010; González, Lucena, Tobaria, \& Laserna, 2009).

Певні переваги для виявлення ВР надає заміна традиційних наносекундних лазерів фемтосекундними, коли короткочасовим фемтосекундним імпульсом вся енергія затримується в об’єкті. У результаті досліджувана речовина швидко іонізується, зменшуються термічні та механічні пошкодження навколо абляційного кратера (Liu, Du, \& Mourou, 1997; Colombier, Combis, Bonneau, Harzic, \& Audouard, 2005). Ці переваги роблять фемтосекундні імпульси ідеальними для точної лазерної абляції.

Незважаючи на те, що LIBS є відносно чутливою технікою, здатною виявляти емісію елемента в діапазоні від однієї мільйонної до однієї мільярдної частинки (Miziolek, Palleschi, \& Schechter, 2006), визначити межі виявлення молекулярних сполук, таких як BP, надзвичайно складно, оскільки ідентифікація залежить від більш ніж одного елемента трасування. У цьому разі необхідний комплексний аналіз для вирізнення ВР з-поміж інших органічних матеріалів.

Раманівська спектроскопія - технологія, яка уможливлює ідентифікування невідомих хімічних речовин завдяки реєстрації розсіювання падаючого лазерного випромінювання молекулярними ланцюгами з розділенням його на окремі частоти в унікальному процесі коливання. Коливання хімічних зв'язків усередині молекули відповідають своєрідному «відбитку», який залежить як від складу речовини, так і від молекулярної структури кожного їі компонента (Steinfeld, \& Wormhoudt, 1998; Moor, 2004).

Завдяки можливості майже миттєво отримати результат дослідження, а також здійснити аналіз досліджуваних зразків речовин на певній відстані від приладу цей вид спектроскопії доволі перспективний (Izake, 2010; Weyermann et al., 2011). Основною проблемою його реалізації $є$ так зване розсіювання Рейліха, яке в багатьох випадках маскує слабкі раманівські сигнали. Підвищити їх інтенсивність можна ультрафіолетовим опроміненням досліджуваної поверхні, речовини тощо. Крім того, підвищують чутливість методу, використовуючи поверхнево підсилену раманівську спектроскопію (Surface-enhanced Raman scattering, далі - SERS) (Botti et al., 2013). Надзвичайні можливості SERS зумовлені електромагнітним ефектом через колективні делокалізовані електронні коливання на нерівних металевих поверхнях і підвищенням здатності до поляризації адсорбованих молекул на поверхнях металів, коли застосовується механізм перенесення заряду, отриманого внаслідок цієї взаємодії. Підсилюється сигнал завдяки використанню наночастинок $\mathrm{Au} / \mathrm{Ag}$, гібридних наноструктур, модифікованих колоїдних систем, активних субстратів (Klarite $^{\mathrm{Tm}}$, Renishaw), а також ïx різноманітному поєднанню між собою або з іншими компонентами, що дає змогу знизити рівень детектування ВР до $10^{-10}-10^{-4}$ моль/л $\left(10^{-15}-10^{-6}\right.$ г) залежно від виду ВР (Zapata, López-López, \& García-Ruiz, 2016).

Технологію виявлення та ідентифікації ВР на відстані до 7 м у лабораторних умовах та в умовах темряви для мінімізації перешкод (Pacheco-Londono, Ortiz-Rivera, Primera- 
Pedrozo, \& Hernandez-Rivera, 2009) Шведське агентство оборонних досліджень адаптувало до різних умов навколишнього середовища. Ідентифікувалися ВР як у звичайних скляних пляшках зеленого та коричневого кольору, так і в ПЕТ-контейнерах на відстані від 20 до 55 м (Pettersson, Johansson, Wallin, Nordberg, \& Ustmark, 2009). Погодні умови майже не впливали на результати вимірювання.

Нелінійно-оптичним аналогом RS $є$ метод когерентного антистоксового розсіювання світла (Coherent Anti-Stokes Raman scattering, далі - CARS) (Ahmanov, \& Koroteev, 1977). Метод CARS, уможливлюючи вивчення структури та будови речовини за спектром розсіяного світла, має низку переваг порівняно з RS, основна з яких - використання чітко сфокусованих променів для досягнення умов збіжності фаз, необхідних для когерентності процесу. Ідентифікація досліджуваного зразка із заданою коливальною частотою може бути використана для визначення просторового розподілу активних коливальних раманівських переходів на цій частоті (DemtrYoder, 1985; Li et al., 2009, Optical Express; Li et al., 2009, Applied Optics). Із використанням лазерного випромінювання в фемтосекундному діапазоні довжини імпульсів (Katz, Natan, Silberberg, \& Rosenwaks, 2008; Li et al., 2009, Optical Express; Li et al., 2009, Applied Optics) метод CARS на порядок чутливіший, ніж метод когерентної спектроскопії, уможливлюючи виявлення ВР за концентрацій до 2 мкг/ $\mathrm{cm}^{2}$. Крім того, уведено (Bremer, Wrzesinski, Butcher, Lozovoy, \& Dantusa, 2011) поняття модальності відображення - створено модель, яка візуально демонструє чутливість і селективність методу. А отже вибіркове виявлення слідів ВР набуло перспектив.

Виявлення ВР та їх слідових кількостей на відстані за допомогою терагерцової спектроскопії (далі - THz) базується на розрахунку кількості THz-імпульсів, які відбиваються або проходять крізь досліджуваний зразок (речовину), внаслідок зміни електричного поля цих імпульсів (Kong, \& Wu, 2006). Технологія слугує для виявлення не лише $\mathrm{BP}$, а й зброї та інших прихованих предметів у багажі або під одягом. Терагерцове випромінювання лежить в інфрачервоній області від 0,1 до 10 ТГц (більшість ВР та вибухонебезпечних сполук мають спектральні відбитки в межах цього діапазону (Shen, Taday, \& Kemp, 2004), а отже хвилі можуть проникати крізь неполярні діелектричні матеріали, такі як тканини, дерево або шкіра. Крім того, енергія фотонів у мільйон разів більша за рентгенівські промені.

Результати досліджень (Chen et al., 2007), коли з використанням THz-спектроскопії були отримані спектри поглинання сімнадцяти різноманітних ВР та вибухонебезпечних сполук, характерні смуги поглинання більшості з яких перебували в діапазоні 0,1-2,8 ТГц, становили основу формування бази даних ВР для THz-спектрометрів (Giles, Burnett, Fan, Linfield, \& Cunningham, 2008). Ця технологія спектроскопії має певні переваги, але через суттєві недоліки, такі як низька швидкість частоти кадрів, згасання інтенсивності фотонів зі збільшенням відстані до досліджуваного об'єкта, поглинання випромінювання ТГц водяною парою в повітрі, не може вважатися перспективною при виявленні ВР на великих відстанях (Federici et al., 2005).

Поєднання (комбінування) різних спектроскопічних методів дає змогу отримати значно більше інформації про досліджувану речовину. Зокрема, збільшується ймовірність виявлення ВР і зменшується кількість хибно позитивних результатів. Переваги комбінації методів найбільш чітко проявилися у сфері аналітичного розділення, коли оптичні та масспектрометричні методи були об'єднані з хроматографією або капілярним електрофорезом для відокремлення та подальшого визначення речовин у суміші. 
Додаткову інформацію для виявлення та ідентифікації ВР можна отримати поєднанням LIBS з іншими методами оптичної спектроскопії (Cheng, Li, Liu, \& Wu, 2010).

Як приклад комбінованої спектроскопії, доповнюють один одного методи LIBS i RS. Маючи аналогічні оптичні детектори, а також деякі спільні пристрої (лазер, дзеркала, об'єктив для передачі світла), така комбінація методів дає змогу отримати вичерпну інформацію про невідомі зразки: елементний склад і конфігурацію молекул (Moros, Lorenzo, Lucena, Tobaria, \& Laserna, 2010; Moros, Lorenzo, \& Laserna, 2011; Lin, Niu, Wang, $\mathrm{Yu}, \&$ Duan, 2013). 3 огляду на зазначене ця комбінаційна технологія удосконалюється (Lin, Wang, Guo, Tian, \& Duan, 2018).

Ще одним прикладом комбінованої спектроскопії є аналітичний комплекс методів IMS-mass spectrometry (далі - IMS-MS), в якому IMS відповідає за розділення іонів газової фази, а за допомогою MS визначають компоненти, які містить зразок досліджуваної речовини (Du et al., 2018).

Суттєві переваги, якщо порівняти із технікою LIBS, має Раман-детектор, принцип роботи якого засновано на комбінації підсиленої УФ-променями RS та індукованої лазером люмінесцентної спектроскопії. Насамперед це стосується використання безпечного лазера, який не пошкоджує аналізовану поверхню. Важливо й те, що виявлення ВР грунтується на унікальній молекулярній структурі досліджуваних сполук, що суттєво знижує ризик хибно позитивних (хибно негативних) результатів (Nagli, \& Gaft, 2007).

Висновки. Розглянуті спектометричні методи - невелика частина методів, які можуть застосовуватися для виявлення та аналізу ВР і продуктів вибуху. Їх використання в лабораторних умовах дає змогу підвищити якість збирання інформації про об'єкти дослідження та покращує їх кількісний і якісний аналіз. Разом із низкою переваг спектроскопічних методів аналізу (швидкість, інформативність, висока селективність, відсутність пробопідготовки) суттєвими недоліками більшості з них є те, що для правильної інтерпретації отриманих результатів у разі їх застосування, незважаючи на функціонування бібліотек речовин, потрібні еталони і стандартні розчини.

Розвиток технологій виявлення ВР, безумовно, залишається активною широкомасштабною цариною наукових розвідок для убезпечення пересічних громадян, а також відновлення середовищ з високим ризиком для життя (наприклад, очищення мінних полів). 3 найважливіших завдань при цьому - забезпечення їх портативності, застосування нанотехнологій, які уможливлюють розвиток нових і вдосконалення наявних технологій ідентифікації. Не втрачають своєї наукової актуальності й питання підвищення чутливості та селективності технологій виявлення ВР.

\section{References}

Ahmanov, S. A., \& Koroteev, N. I. (1977). Spektroskopiya rasseyaniya sveta i nelineynaya optika, nelineynoopticheskie metodyi aktivnoy spektroskopii kombinatsionnogo i releevskogo rasseivaniya. Uspehi fizicheskih nauk (№ 123, s. 405-471).

Bohling, C., Hohmann, K., Scheel, D., Bauer, C., Schippers, W., Burgmeier, J. ... Schade, W. (2007). All-fiber-coupled laser-induced breakdown spectroscopy sensor for hazardous materials analysis, Spectrochimica Acta. Part B: Atomic Spectroscopy (Vol. 62, p. 1519-1527). doi: 10.1016/j.sab.2007.10.038.

Borsdorf, H., \& Eiceman, G. (2006). Ion Mobility Spectrometry: Principles and Applications orf. Journal Applied Spectroscopy Reviews (№ 41 (4), p. 323-375). doi: 10.1080/05704920600663469.

Botti, S., Almaviva, S., Cantarini, L., Palucci, A., Puiu, A., \& Rufoloni, A. (2013). Trace level detection and identification of nitro-based explosives by surface-enhanced Raman spectroscopy. Journal of Raman spectros$\operatorname{copy}$ (№ 44 (3), p. 463-468). doi: 10.1002/jrs.4203. 
Bremer, M. T., Wrzesinski, P. J., Butcher, N., Lozovoy, V. V., \& Dantusa, M. (2011). Highly selective standoff detection and imaging of trace chemicals in a complex background using single-beam coherent anti-Stokes Raman scattering. Applied Physics Letters (№ 99 (10), p. 101109). doi: 10.1063/1.3636436.

Buryakov, I. A. (2011). Obnaruzhenie vzryivchatyih veschestv metodom spektrometrii ionnoy podvizhnosti. Zhurnal analiticheskoy himii (№ 66 (8), s. 788-809).

Cheng, Cheng, Li, Zhenyu, Liu, Weihao, \& Wu, Jing (2010). Stand-Off Explosives Detection Based on Raman Spectroscopy. Symposium on Photonics and Optoelectronics. Chengdu, China: IEEE. doi: 10.1109/SOPO.2010.5504012.

Chen, J., Chen, Y., Zhao, H., Glenn, J., Bastiaans, \& Zhang, X.-C. (2007). Absorption coefficients of selected explosives and related compounds in the range of 0.1-2.8 THz, Optics Express (Vol. 15. Issue 19, p. 1206012067). doi: 10.1364/OE.15.012060.

Colombier, J. P., Combis, P., Bonneau, F., Harzic, R. Le, \& Audouard, E. (2005). Hydrodynamic simulations of metal ablation by femtosecond laser irradiation. Physical Review B (№ 71 (16), p. 165406). doi: 10.1103/ PhysRevB.71.165406.

Ctvrtnickova, T., Mateo, M. P., Yanez, A., \& Nicolas, G. (2011). Application of LIBS and TMA for the determination of combustion predictive indices of coals and coal blends. Applied Surface Science (№ 257 (12), p. 5447-5451). doi: 10.1016/j.apsusc.2010.12.025.

DemtrYoder, V. (1985). Lazernaya spektroskopiya. Osnovnyie printsipyi i tehnika eksperimenta. M.: Nauka. 608 s.

De Lucia, F. C. Jr., Gottfried, J. L., Munson, C. A., \& Miziolek, A. W. (2007). Double pulse laser-induced breakdown spectroscopy of explosives: Initial study towards improved discrimination, Spectrochimica Acta. Part B: Atomic Spectroscopy (Vol. 62, Issue 12, p. 1399-1404). doi: 10.1016/j.sab.2007.10.036.

Du, Z., Sun, T., Zhao, J., Wang, D., Zhang, Z., \& Yu, W. (2018). Development of a plug-type IMS-MS instrument and its applications in resolving problems existing in in-situ detection of illicit drugs and explosives by IMS. Talanta (№ 184, p. 65-72). doi: 10.1016/j.talanta.2018.02.086.

Existing and potential standoff explosives detection techniques. (2004). Washington DC: National Academies Press. doi: 10.17226/10998.

Federici, J.F., Schulkin, B., Huang, F., Gary, D., Barat, R., Oliveira, F., \& Zimdars, D. (2005). THz imaging and sensing for security applications - explosives, weapons and drugs. Semiconductor Science And Technology (№ 20, p. 266-280). doi: 10.1088/0268-1242/20/7/018.

Furton, K. G., \& Myers, L. J. (2001). The scientific foundation and efficacy of the use of canines as chemical detectors for explosives. Talanta (№ 54, p. 487-500).

Gorbachev, Yu. P., Ionov, V. V., \& Kolomiets, Yu. N. (2006). Patent Rossiyskoy Federatsii 2279051. M.: Rospatent. Gorbachev, Yu. P., Ionov, V. V., \& Kolomiets, Yu. N. (2008). Patent Rossiyskoy Federatsii 2325628. M.: Rospatent. Giles, A., Burnett, A. D., Fan, W., Linfield, E. H., \& Cunningham, J. E. (2008). Terahertz spectroscopy of explosives and drugs. Materials Today (№ 11 (3), p. 18-26). doi: 10.1016/S1369-7021(08)70016-6.

González, R., Lucena, P., Tobaria, L. M., \& Laserna, J. J. (2009). Standoff LIBS detection of explosive residues behind a barrier, Journal of Analytical Atomic Spectrometry (Vol. 24. Issue 8, p. 1123-1126). doi: 10.1039/ B821566A.

Gottfried, J. L., De Lucia, F. C. Jr., Munson, C. A., \& Miziolek, A. W. (2009). Laser-induced breakdown spectroscopy for detection of explosives residues: a review of recent advances, challenges, and future prospects. Analytical and Bioanalytical Chemistry (№ 395 (2), p. 283-300). doi: 10.1007/s00216-009-2802-0.

Izake, E. L. (2010). Forensic and homeland security applications of modern portable Raman spectroscopy, Forensic Science International (Vol. 202, p. 1-8). doi:10.1016/j.forsciint.2010.03.020.

Jeannette, M. Perr, Kenneth, G. Furton, \& Almirall, Josh R. (2005). Solid phase microextraction ion mobility spectrometer interface for explosive and taggant detection. Journal of separation science (№ 28 (2), p. 177-183). doi: 10.1002/jssc.200401893.

Katz, O., Natan, A., Silberberg, Y., \& Rosenwaks, S. (2008). Standoff detection of solid traces by single-beam nonlinear Raman spectroscopy using shaped femtosecond pulses. Applied Physics Letters (№ 92, 171116. doi: $10.1063 / 1.2918014 /$.

Kong, S., \& Wu, D. (2006). Terahertz Time-Domain Spectroscopy for Explosive Trace Detection, IEEE International conference on computational intelligence for homeland security and personal safety. Alexandria, VA, USA (p. 47-50). doi: 10.1109/CIHSPS.2006.313311.

Lazic, V., Palucci, A., Jovicevic, S., Carapanese, M., Poggi, C., \& Buono, E. (2010). Detection of explosives at trace levels by Laser Induced Breakdown Spectroscopy (LIBS), Chemical, Biological, Radiological, Nuclear and Explosives (CBRNE) Sensing XI. Materials of SPIE 7665. Orlando, Florida. doi: 10.1117/12.850717. 
Leggett, D. C., Jenkins, T. F., \& Murrmann, R. P. (1971). Corps of Engineers. U.S. Army. Cold Regions Research and Engineering Laboratory. Special Report. Hanover: NH (p. 77-116).

Li, H., Harris, D., Xu, B., Wrzesinski, P., Lozovoy, V., \& Dantus, M. (2009). Coherent mode-selective Raman excitation towards standoff detection. Optical Express (№ 16 (8), p. 5499-5504). doi: 10.1364/OE.16.005499.

Li, H., Harris, D., Xu, B., Wrzesinski, P. J., Lozovoy, V.V., \& Dantus, M. (2009). Standoff and arms-length detection of chemicals with single-beam coherent anti-Stokes Raman scattering. Applied Optics (№ 48 (4), p. B17-B22). doi: 10.1364/AO.48.000B17.

Lin, Q., Niu, G., Wang, Q., Yu, Q., \& Duan, Y. (2013). Combined laser-induced breakdown with Raman spectroscopy: historical technology development and recent applications. Applied Spectroscopy Review (№ 48 (6), p. 487-508). doi: 10.1080/05704928.2012.751028.

Lin, Q., Wang, S., Guo, G., Tian, Y., \& Duan, Y. (2018). Novel Laser Induced Breakdown Spectroscopy - Raman Instrumentation Using a Single Pulsed Laser and an Echelle Spectrometer. Journal Instrumentation Science \& Technology (№ 46 (2), p. 163-174). doi: 10.1080/10739149.2017.1344702.

Liu, X., Du, D., \& Mourou, G. (1997). Laser ablation and micromachining with ultrashort laser pulses. IEEE Journal of Quantum Electronics (№ 33 (10), p. 1706-1716). doi: 10.1109/3.631270.

Lucena, P., Dona, A., Tobaria, L. M., \& Laserna, J. J. (2011). New challenges and insights in the detection and spectral identification of organic explosives by laser induced breakdown spectroscopy, Spectrochimica Acta. Part B: Atomic Spectroscopy (Vol. 66. Issue 1, p. 12-20). doi: 10.1016/j.sab.2010.11.012.

Manoj, Kumar Gundawar, Junjuri, Rajendhar, \& Myakalwar, Ashwin Kumar (2017). Standoff detection of explosives at $1 \mathrm{~m}$ using laser induced breakdown spectroscopy. Defence Science Journal (№ 67 (6), p. 623-630). doi: $10.14429 /$ dsj.67.11498.

Miziolek, A., Palleschi, V., \& Schechter, I. (2006). Laser Induced Breakdown Spectroscopy (LIBS). Cambridge, UK: Cambridge University Press. doi: 10.1017/CBO9780511541261.

Moor, D. (2004). Instrumentation for trace detection of high explosives. Review of Scientific Instruments (№ 75, p. 2449-2512). doi.org/10.1063/1.1771493.

Moros, J., Lorenzo, J. A., Lucena, P., Tobaria, L. M., \& Laserna, J. J. (2010). Simultaneous Raman spectroscopy-laser-induced breakdown spectroscopyfor instant standoff analysis of explosives using a mobile integrated sensor platform. Analytical Chemistry (№ 82 (4), p. 1389-1400). doi: 10.1021/ac902470v.

Moros, J., Lorenzo, J., \& Laserna, J. (2011). Standoff detection of explosives: critical comparison for ensuing options on Raman spectroscopy - LIBS sensor fusion. Analytical and Bioanalytical Chemistry (№ 400 (10), p. 3353-3365). doi: 10.1007/s00216-011-4999-y.

Murrmann, R. P., Jenkins, T. F., \& Leggett, D. C. (1971). US Army Cold Regions Research and Engineering Laboratory: Special Report. Hanover: NH. 158 p.

Nagli, L., \& Gaft, M. (2007). Raman scattering spectroscopy for explosives identification. SPIE, the international society for optics and photonics. Bellingham, WA (p. 6552-6562). doi: 10.1117/12.719319.

Pacheco-Londono, L. C., Ortiz-Rivera, W., Primera-Pedrozo, O. M., \& Hernandez-Rivera, S. P. (2009). Vibrational spectroscopy standoff detection of explosives, Analytical and Bioanalytical Chemistry (Vol. 395. Issue 2, p. 323-335). doi: 10.1007/s00216-009-2954-y.

Pettersson, A., Johansson, I., Wallin, S., Nordberg, M., \& Ustmark, H. (2009). Near real-time standoff detection of explosives in a realistic outdoor environment at 55m distance, Propellants, Explosives, Pyrotechnics (Vol. 34. Issue 4, p. 297-306). doi: 10.1002/prep.200800055.

Shen, Yaochun, Taday, Philip F., \& Kemp, Michael C. (2004). Terahertz spectroscopy of explosive materials, Proceedings of SPIE (Vol. 5619, p. 82-89). doi: 10.1117/12.577188.

Sreedhar, S., Gundawar, M. K., \& Rao, S. V. (2014). Laser induced breakdown spectroscopy for classification of high energy materials using elemental intensity ratios. Defence science journal (№ 64 (4), p. 332-338). doi: $10.14429 / \mathrm{dsj} .64 .4741$.

Steinfeld, J., \& Wormhoudt, J. (1998). Explosives detection: a challenge for physical chemistry. Annual Review of Physical Chemistry (№ 49, p. 203-232). doi: 10.1146/annurev.physchem.49.1.203.

Weyermann, C., Mimoune, Y., Anglada, F., Massonnet, G., Esseiva, P., \& Buzzini, P. (2011). Applications of a transportable Raman spectrometer for the in situ detection of controlled substances at border controls. Forensic Science International (№ 209, p. 21-28). doi: 10.1016/j.forsciint.2010.11.027.

Zapata, F., López-López, M., \& García-Ruiz, C. (2016). Detection and identification of explosives by surface enhanced Raman scattering, Journal Applied Spectroscopy Reviews (Vol. 51. Issue 3, p. 227-262). doi: 10.1080/05704928.2015.1118637. 


\section{Список використаних джерел}

Ахманов, С. А., \& Коротеев, Н. И. (1977). Спектроскопия рассеяния света и нелинейная оптика, нелинейнооптические методы активной спектроскопии комбинационного и рэлеевского рассеивания. Успехи физических наук (№ 123, с. 405-471).

Bohling, C., Hohmann, K., Scheel, D., Bauer, C., Schippers, W., Burgmeier, J. ... Schade, W. (2007). All-fibercoupled laser-induced breakdown spectroscopy sensor for hazardous materials analysis, Spectrochimica Acta. Part B: Atomic Spectroscopy (Vol. 62, p. 1519-1527). doi: 10.1016/j.sab.2007.10.038.

Borsdorf, H., \& Eiceman, G. (2006). Ion Mobility Spectrometry: Principles and Applications orf. Journal Applied Spectroscopy Reviews (№ 41 (4), p. 323-375). doi: 10.1080/05704920600663469.

Botti, S., Almaviva, S., Cantarini, L., Palucci, A., Puiu, A., \& Rufoloni, A. (2013). Trace level detection and identification of nitro-based explosives by surface-enhanced Raman spectroscopy. Journal of Raman spectroscop (№ 44 (3), p. 463-468). doi: 10.1002/jrs.4203.

Bremer, M. T., Wrzesinski, P. J., Butcher, N., Lozovoy, V. V., \& Dantusa, M. (2011). Highly selective standoff detection and imaging of trace chemicals in a complex background using single-beam coherent antiStokes Raman scattering. Applied Physics Letters (№ 99 (10), p. 101109). doi: 10.1063/1.3636436.

Буряков, И. А. (2011). Обнаружение взрывчатых веществ методом спектрометрии ионной подвижности. Журнал аналитической химии (№ 66 (8), с. 788-809).

Cheng, Cheng, Li, Zhenyu, Liu, Weihao, \& Wu, Jing (2010). Stand-Off Explosives Detection Based on Raman Spectroscopy. Symposium on Photonics and Optoelectronics. Chengdu, China: IEEE. doi: 10.1109/ SOPO.2010.5504012.

Chen, J., Chen, Y., Zhao, H., Glenn, J., Bastiaans, \& Zhang, X.-C. (2007). Absorption coefficients of selected explosives and related compounds in the range of 0.1-2.8 THz, Optics Express (Vol. 15, Issue 19, p. 1206012067). doi: 10.1364/OE.15.012060.

Colombier, J. P., Combis, P., Bonneau, F., Harzic, R. Le, \& Audouard, E. (2005). Hydrodynamic simulations of metal ablation by femtosecond laser irradiation. Physical Review B. (№ 71 (16), p. 165406). doi: 10.1103/ PhysRevB.71.165406.

Ctvrtnickova, T., Mateo, M. P., Yanez, A., \& Nicolas, G. (2011). Application of LIBS and TMA for the determination of combustion predictive indices of coals and coal blends. Applied Surface Science (№ 257 (12), p. 5447-5451). doi: 10.1016/j.apsusc.2010.12.025.

Демтрёдер, В. (1985). Лазерная спектроскопия. Основные принципы и техника эксперимента. М.: Наука. $608 \mathrm{c}$.

De Lucia, F. C. Jr., Gottfried, J. L., Munson, C. A., \& Miziolek, A. W. (2007). Double pulse laser-induced breakdown spectroscopy of explosives: Initial study towards improved discrimination, Spectrochimica Acta. Part B: Atomic Spectroscopy (Vol. 62, Issue 12, p. 1399-1404). doi: 10.1016/j.sab.2007.10.036.

Du, Z., Sun, T., Zhao, J., Wang, D., Zhang, Z., \& Yu, W. (2018). Development of a plug-type IMS-MS instrument and its applications in resolving problems existing in in-situ detection of illicit drugs and explosives by IMS. Talanta (№ 184, p. 65-72). doi: 10.1016/j.talanta.2018.02.086.

Existing and potential standoff explosives detection techniques. (2004). Washington DC: National Academies Press. doi: 10.17226/10998.

Federici, J. F., Schulkin, B., Huang, F., Gary, D., Barat, R., Oliveira, F., \& Zimdars, D. (2005). THz imaging and sensing for security applications - explosives, weapons and drugs. Semiconductor Science And Technology (№ 20, p. 266-280). doi: 10.1088/0268-1242/20/7/018.

Furton, K. G., \& Myers, L. J. (2001). The scientific foundation and efficacy of the use of canines as chemical detectors for explosives. Talanta (№ 54, p. 487-500).

Горбачев, Ю. П., Ионов, В. В., \& Коломиец, Ю. Н. (2006). Патент Российской Федерации 2279051. М.: Роспатент.

Горбачев, Ю. П., Ионов, В. В., \& Коломиец, Ю. Н. (2008). Патент Российской Федерации 2325628. М.: Роспатент.

Giles, A., Burnett, A. D., Fan, W., Linfield, E. H. \& Cunningham, J. E. (2008). Terahertz spectroscopy of explosives and drugs. Materials Today (№ 11 (3), p. 18-26). doi: 10.1016/S1369-7021(08)70016-6.

González, R., Lucena, P., Tobaria, L. M., \& Laserna, J. J. (2009). Standoff LIBS detection of explosive residues behind a barrier, Journal of Analytical Atomic Spectrometry (Vol. 24. Issue 8, p. 1123-1126). doi: 10.1039/ B821566A. 
Gottfried, J. L., De Lucia, F. C. Jr, Munson, C. A., \& Miziolek, A. W. (2009). Laser-induced breakdown spectroscopy for detection of explosives residues: a review of recent advances, challenges, and future prospects. Analytical and Bioanalytical Chemistry (№ 395 (2), p. 283-300). doi: 10.1007/s00216-009-2802-0.

Izake, E. L. (2010). Forensic and homeland security applications of modern portable Raman spectroscopy, Forensic Science International (Vol. 202, p. 1-8). doi:10.1016/j.forsciint.2010.03.020.

Jeannette, M. Perr, Kenneth, G. Furton, \& Almirall, Josh R. (2005). Solid phase microextraction ion mobility spectrometer interface for explosive and taggant detection. Journal of separation science (№ 28 (2), p. 177183). doi: $10.1002 /$ jssc.200401893.

Katz, O., Natan, A., Silberberg, Y., \& Rosenwaks, S. (2008). Standoff detection of solid traces by single-beam nonlinear Raman spectroscopy using shaped femtosecond pulses. Applied Physics Letters. (№ 92.171116. doi: $10.1063 / 1.2918014 /$.

Kong, S., \& Wu, D. (2006). Terahertz Time-Domain Spectroscopy for Explosive Trace Detection, IEEE International conference on computational intelligence for homeland security and personal safety. Alexandria, VA, USA (p. 47-50). doi: 10.1109/CIHSPS.2006.313311.

Lazic, V., Palucci, A., Jovicevic, S., Carapanese, M., Poggi, C., \& Buono, E. (2010). Detection of explosives at trace levels by Laser Induced Breakdown Spectroscopy (LIBS), Chemical, Biological, Radiological, Nuclear and Explosives (CBRNE) Sensing XI. Materials of SPIE 7665. Orlando, Florida. doi: 10.1117/12.850717.

Leggett, D. C., Jenkins, T. ., \& Murrmann, R. P. (1971). Corps of Engineers. U.S. Army. Cold Regions Research and Engineering Laboratory. Special Report. Hanover: NH (p. 77-116).

Li, H., Harris, D., Xu, B., Wrzesinski, P., Lozovoy, V., \& Dantus, M. (2009). Coherent mode-selective Raman excitation towards standoff detection. Optical Express (№ 16 (8), p. 5499-5504). doi: 10.1364/ OE.16.005499.

Li, H., Harris, D., Xu, B., Wrzesinski, P. J., Lozovoy, V.V., \& Dantus, M. (2009). Standoff and arms-length detection of chemicals with single-beam coherent anti-Stokes Raman scattering. Applied Optics (№ 48 (4), p. B17-B22). doi: 10.1364/AO.48.000B17.

Lin, Q., Niu, G., Wang, Q., Yu, Q., \& Duan, Y. (2013). Combined laser-induced breakdown with Raman spectroscopy: historical technology development and recent applications. Applied Spectroscopy Review (№ 48 (6), p. 487-508). doi: 10.1080/05704928.2012.751028.

Lin, Q., Wang, S., Guo, G., Tian, Y., \& Duan, Y. (2018). Novel Laser Induced Breakdown Spectroscopy - Raman Instrumentation Using a Single Pulsed Laser and an Echelle Spectrometer. Journal Instrumentation Science \& Technology (№ 46 (2), p. 163-174). doi: 10.1080/10739149.2017.1344702.

Liu, X., Du, D., \& Mourou, G. (1997). Laser ablation and micromachining with ultrashort laser pulses. IEEE Journal of Quantum Electronics (№ 33 (10), p. 1706-1716). doi: 10.1109/3.631270.

Lucena, P., Dona, A., Tobaria, L. M., \& Laserna, J. J. (2011). New challenges and insights in the detection and spectral identification of organic explosives by laser induced breakdown spectroscopy, Spectrochimica Acta. Part B: Atomic Spectroscopy (Vol. 66. Issue 1, p. 12-20). doi: 10.1016/j.sab.2010.11.012.

Manoj, Kumar Gundawar, Junjuri, Rajendhar, \& Myakalwar, Ashwin Kumar (2017). Standoff detection of explosives at $1 \mathrm{~m}$ using laser induced breakdown spectroscopy. Defence Science Journal (№ 67 (6), p. 623-630). doi: $10.14429 /$ dsj.67.11498.

Miziolek, A., Palleschi, V., \& Schechter, I. (2006). Laser Induced Breakdown Spectroscopy (LIBS). Cambridge, UK: Cambridge University Press. doi: 10.1017/CBO9780511541261.

Moor, D. (2004). Instrumentation for trace detection of high explosives. Review of Scientific Instruments. (№ 75, p. 2449-2512). doi.org/10.1063/1.1771493.

Moros, J., Lorenzo, J. A., Lucena, P., Tobaria, L. M., \& Laserna, J. J. (2010). Simultaneous Raman spectroscopylaser-induced breakdown spectroscopyfor instant standoff analysis of explosives using a mobile integrated sensor platform. Analytical Chemistry (№ 82 (4), p. 1389-1400). doi: 10.1021/ac902470v.

Moros, J., Lorenzo, J., \& Laserna, J. (2011). Standoff detection of explosives: critical comparison for ensuing options on Raman spectroscopy - LIBS sensor fusion. Analytical and Bioanalytical Chemistry (№ 400 (10), p. 3353-3365). doi: 10.1007/s00216-011-4999-y.

Murrmann, R. P., Jenkins, T. F., \& Leggett, D. C. (1971). US Army Cold Regions Research and Engineering Laboratory: Special Report. Hanover: NH. 158 p.

Nagli, L., \& Gaft, M. (2007). Raman scattering spectroscopy for explosives identification. SPIE, the international society for optics and photonics. Bellingham, WA (p. 6552-6562). doi: 10.1117/12.719319. 
Pacheco-Londono, L. C., Ortiz-Rivera, W., Primera-Pedrozo, O. M., \& Hernandez-Rivera, S. P. (2009). Vibrational spectroscopy standoff detection of explosives, Analytical and Bioanalytical Chemistry (Vol. 395. Issue 2, p. 323-335). doi: 10.1007/s00216-009-2954-y.

Pettersson, A., Johansson, I., Wallin, S., Nordberg, M., \& Ustmark, H. (2009). Near real-time standoff detection of explosives in a realistic outdoor environment at 55m distance, Propellants, Explosives, Pyrotechnics (Vol. 34. Issue 4, p. 297-306). doi: 10.1002/prep.200800055.

Shen, Yaochun, Taday, Philip F., \& Kemp, Michael C. (2004). Terahertz spectroscopy of explosive materials, Proceedings of SPIE (Vol. 5619, p. 82-89). doi: 10.1117/12.577188.

Sreedhar, S., Gundawar, M. K., \& Rao, S. V. (2014). Laser induced breakdown spectroscopy for classification of high energy materials using elemental intensity ratios. Defence science journal (№ 64 (4), p. 332-338). doi: $10.14429 / \mathrm{dsj} .64 .4741$.

Steinfeld, J., \& Wormhoudt, J. (1998). Explosives detection: a challenge for physical chemistry. Annual Review of Physical Chemistry (№ 49, p. 203-232). doi: 10.1146/annurev.physchem.49.1.203.

Weyermann, C., Mimoune, Y., Anglada, F., Massonnet, G., Esseiva, P., \& Buzzini, P. (2011). Applications of a transportable Raman spectrometer for the in situ detection of controlled substances at border controls. Forensic Science International (№ 209, p. 21-28). doi: 10.1016/j.forsciint.2010.11.027.

Zapata, F., López-López, M., \& García-Ruiz, C. (2016). Detection and identification of explosives by surface enhanced Raman scattering, Journal Applied Spectroscopy Reviews (Vol. 51. Issue 3, p. 227-262). doi: 10.1080/05704928.2015.1118637. 